\title{
Investigating the process of learning for school pupils on residential outdoor education courses
}

\section{Roger Scrutton ${ }^{1}$}

Published online: 11 December 2019

(C) The Author(s) 2019

\begin{abstract}
Pupils' process of learning on residential outdoor education courses is perceived by some providers, customers and researchers as a linear one in which learning takes place in the social affective domain followed by the academic affective domain and then, depending on course objectives, the cognitive domain. Other researchers envisage a non-linear process, akin to soft complexity, in which the inputs are the course characteristics and traits of the learner and the process an 'intertwining' and feedforward and feedback between learning domains. These theses are investigated with reference to the objectives of different course types - adventure, curriculum, combined - and it is concluded that while individual pupils learn in a complex way, outcomes at the level of the group and/or course appear to be linearly related. However, there is a question over whether a curriculum-related course can deliver the affective learning that seems to facilitate cognitive learning. This was tested experimentally with secondary school pupils attending a field studies (curriculum) course. Although the experimental group made significant cognitive gain it was not accompanied by the putative affective learning. Affective measures revealed a level of stability of pupils' self-concept that might have inhibited affective learning. There remains potential for primary quantitative studies to test for relationships between elements of learning in different domains on residential courses and thus inform the process of learning.
\end{abstract}

Keywords Residential outdoor education · Learning processes · Quantitative testing

\section{Introduction}

Residential outdoor education courses for school pupils are widely credited with having a positive impact on pupils' personal, social and academic development (Fiennes et al.

Roger Scrutton

roger.scrutton@ed.ac.uk

1 Moray House School of Education, University of Edinburgh, Holyrood Road, Edinburgh EH8 $8 \mathrm{AQ}$, Scotland 
2015; Malone and Waite 2016). Both qualitative and quantitative research into residential interventions have found improvements in personal and social skills, attitude towards school work and academic achievement and attainment (e.g. Hattie et al. 1997; Kendall and Rodger 2015; Nundy 1999). Moreover, the qualitative evidence from teachers and pupils reveals a perceived linear process of learning in which the improvements in personal and social skills foster a better attitude towards school work leading to greater academic achievement (Scrutton 2014). Here, we critically examine the reality of this perceived linear process. In doing so, the three elements of it are referred to as social-affective, academic-affective (c.f. conative) and cognitive learning respectively, to mirror the classification of learning domains recognised in the Taxonomy of Educational Objectives project described by Bloom et al. (1956) and Krathwohl et al. (1964).

While educational research elucidates learning processes, the experience of course providers of what works to deliver the outcomes desired by education leaders, teachers and their pupils has led to an evolution in residential course types that seems to acknowledge the linear pathway concept. At primary or junior school level the adventure course aimed at delivering personal and social development remains popular, with teachers observing parallel and subsequent improvements in areas of academic affective and cognitive learning (e.g. Nundy 1999; Amos and Reiss 2012; Kendall and Rodger 2015). At secondary or high school level, and in colleges and universities, the residential curriculum-related course, e.g. field studies, is recognised as delivering significant cognitive gain. In some cases this course type is also credited with delivering precursor or concomitant affective gains (e.g. Boyle et al. 2007; Elkins and Elkins 2007). A third course type has become popular in recent years combining adventure and curriculum components and developed as an option for both primary and secondary schools, the rationale being that affective learning engendered by the adventure component stimulates parallel or subsequent cognitive learning (Nundy 1999; Amos and Reiss 2012), as exemplified by the option "Adventure Education: Field" (Experience Outdoors n.d.). A further development in course types emerged from the Learning Away project (Kendall and Rodger 2015) and is now offered by many providers, engaging teachers and pupils in the design of a bespoke course tailored to customer needs, so-called "Brilliant Residentials" (Learning Away n.d.). This encourages the customer to take ownership of the learning outcomes and implement their transfer to school and life in general.

Thus, for the purposes of discussion we might envisage a matrix defined by domains of learning on one axis (informed by research) and course types on the other (informed by practice). It is within this framework that the perceived linear process referred to above is considered. The perception that affective learning appears to facilitate cognitive learning through a linear process will be tested against extensive research into experiential learning processes that suggests an interplay, intertwining or cycling between learning domains (Krathwohl et al. 1964; Schenck and Cruickshank 2015). Whether learning on residential outdoor education courses is a linear or non-linear process is an intriguing question and has the potential to inform the "how and why" of outdoor learning rather than simply the "what works and by how much". The first part of this paper will be devoted to this issue.

Because education is increasingly focused on improving pupil attainment (cognitive gain) - although at the same time acknowledging that the personal and social 
development of pupils is important - it is essential to know if residential courses can deliver the appropriate learning experiences to meet this challenge. Adventure and combined courses clearly provide opportunities for affective learning as a stimulus of cognitive gain, but an important question is whether a curriculum-related course with no adventure component has this capability. Therefore, following the discussion on process, an experiment to discover whether a residential curriculum-based (field studies) course produces both affective learning and cognitive gains, be they sequential or intertwined, is described. There are very few reports in research literature of experiments of this kind.

\section{Existing research evidence for the process of learning}

\section{Perspectives on the process: Linear or non-linear}

The starting point for this investigation is qualitative evidence from teachers, pupils and practitioners pointing to what might be called a linear pathway of learning associated with residential outdoor education courses (Scrutton 2014). For example, the Natural Connections project found that $92 \%$ of responding teachers believed that outdoor learning improves pupils' engagement with academic work and over 50\% believed that this led, in turn, to greater attainment (Waite et al. 2016). This pathway might take on a different form and different timescale depending on course type, but the essential elements, as articulated by teachers and outdoor course providers, seem to be a socialaffective learning phase followed by an academic-affective learning phase followed by a cognitive learning phase in which academic achievement and attainment are improved. Although relating specifically to curriculum-related (field studies) courses in the higher education sector, Boyle et al. (2007, p. 301) claim that "a positive outcome in the affective domain is considered to be an important antecedent to success in the cognitive domain". In support of such claims, research in other branches of education shows how interventions in schools to improve pupils' academic-affective competencies lead to improved academic performance (Christie and Higgins 2012; Durlak et al. 2010; Durlak et al. 2011), and in other studies how feedforward as well as feedback between affective and cognitive learning domains determines a pupils response to cognitive challenges (Dweck and Leggett 1988). Therefore, there is a body of opinion from qualitative research that affective learning facilitates, or is even essential for, cognitive learning.

In quantitative studies there are very few contributions that imply a pathway of learning exploiting both affective and cognitive domains. Understanding cause and effect is particularly problematic. Nundy (1999) describes a mixed methods outdoor education research project in which the outcomes were measured quantitatively using a quasi-experimental method whilst drivers of learning were investigated using qualitative methods. The quantitative element used appropriate questionnaires to measure social-affective, academic-affective and cognitive gains while the qualitative element used a diary-interview approach. Participants were upper primary pupils, with the experimental group attending a residential combined course for one week at the same time as the control group studied the subject matter of the course under classroom conditions. Although both groups made academic-affective and cognitive gains during 
the experiment, the experimental group made significantly greater gains than the control group. Moreover, correlational studies showed that the stronger the academicaffective gain the greater the cognitive gain, but only in the experimental group. Nundy concluded, with regard to cause and effect, that, "positive changes in affective learning appear to lead to positive changes in cognitive learning and that this is enhanced within a residential fieldwork setting" (p.193). In reporting his research, Nundy does not refer to the seminal work of Krathwohl, Bloom and Masia (Krathwohl et al. 1964), in which they propose that in education generally affective and cognitive learning processes are "tightly intertwined", but he does suggest learning in his case "overlaps and intertwines" (p.196), thus hinting at a similar phenomenon. Nundy's qualitative data indicated that, from the pupils' perspective, three elements of the residential course served to facilitate learning: the presence of key episodes or memorable moments, which acted as triggers for the recall of other information; learning strategies, such as discovery learning; and the building of relationships in both social and study contexts.

Other authors have been more explicit about intertwining of learning experiences. McKenzie (2003) reviewed the cyclical model of learning on Outward Bound courses as envisaged by Walsh and Gollins and put forward an alternative model of interacting parallel experiences. In her model the learner interacts simultaneously with the physical environment, the social environment, course activities, acting as a service provider, and the characteristics of the instructors. The mix of course activities defines an adventure, curriculum or combined course. Williams (2013, p.107), in a mixed-methods study, goes further by using "complexity theory to throw light on the synergistic interrelationships between different aspects of [the] experience," advocating a non-linear model in which the factors that lead to affective and cognitive gain work together. However, he concludes that a leap in attainment (cognitive gain) "is unlikely to occur without ... a step change in confidence" (p.120), implying that some affective learning is a necessary precursor to cognitive gain. In comparison with Nundy's qualitative findings, Williams found from pupils that the aspects of outdoor learning contributing towards impact were: living with others; energising influences, such as challenges; teacher relationships; and learning about self.

The factors identified by pupils as facilitating learning in both Nundy's and Williams' mixed methods approaches are quite distinctively features of the affective domain and lend weight to the idea that an affective experience is desirable, if not essential, for "positive changes in cognitive learning" (Nundy 1999, p.193), "a quantum leap [in attainment]" (Williams 2013, p.114), or "success in the cognitive domain" (Boyle et al. 2007, p.301). Nundy and Williams used combined (adventure/curriculum) courses and have confirmed what practitioners believe, that such courses can deliver the affective learning that seems to be desirable. This then raises the question of whether, say, a purely curriculum course (no adventure component) can deliver the desirable affective component. There is some qualitative evidence for this (Boyle et al. 2007; Waite et al. 2016), but quantitative evidence is hard to find.

\footnotetext{
${ }^{1}$ Krathwohl et al. (p.62) refer to intertwined as, "Each affective behaviour has a cognitive-behaviour counterpart of some kind and vice versa.... There is some correlation between the Taxonomy levels of an affective objective and its cognitive counterpart." Intertwining seems to have been used sensu lato to imply interaction or interdependence of the learning domains.
} 
It is clear that some researchers envisage learning on residential courses as essentially a linear process. Indeed, even some neuroscientific research posits a "front-end" of learning, which involves affective processes, and a "back-end" of learning in which cognitive function is enhanced (Schenck and Cruickshank 2015). On the face of it, this might seem to be what is happening in outdoor education. Course providers have found that adventure, curriculum or combined adventure/curriculum courses can deliver the learning outcomes desired from residential courses as demanded by their customers - educators, health professionals, public sector and commercial providers, grant awarding bodies, government departments - or courses can be tailored to do so. In addition, there are common elements of these different courses that pupils themselves see as facilitating their development: living with others and building relationships with peers and teachers in both social and study contexts; energising influences, such as challenges and memorable moments; discovering learning strategies, such as taking ownership of learning; and learning about self. Thus, at the level of what works for practitioners and creates the drivers for learning, the outcomes from a residential outdoor education course are well understood. Given that the underpinning of a successful residential experience is commonly a social one (e.g. communal meals, shared dormitories, group work, evening activities) with academic-affective and cognitive benefits emerging later, it is understandable that the process appears to be linear.

However, other researchers, including those working in cognate fields of educational research, envisage an "intertwining" of learning in different domains, a feedforward and feedback process or even a complex process, rather than a linear one. The fact that the process is in reality a complex one becomes clearer when the prior experiences, motivations, learning preferences and behaviours of individual participants are factored in (McKenzie 2003). The components of the course interact in complex, multiple ways because each individual responds to the components and integrates their effects differently. Cause and effect are personalised. Nevertheless, research using the normative paradigm assumes that in practice we see much the same benefit for the majority of participants even though their individual learning processes differ. Complexity scientists recognise "hard" and "soft" complex systems (Cilliers and Richardson 2001). Soft complexity is recognised at individual and organisational levels and might be an appropriate term to use in the outdoor education context, certainly at the individual level but also at the group level. Davis and Sumara (2006) describe soft complexity as "an approach more common in the biological and social sciences that draws on the metaphors and principles developed within hard complexity science to describe living or social systems." Hence, "in this case, complexity is more a way of seeing the world, an interpretive system" (p.18). Soft complexity better reflects the role that the individual participant's perception of the world plays in the experiential learning process during residential outdoor education courses. Thus, what might appears to be a linear process at the population or sample level is actually a complex one at the level of the individual participant and their contribution to the residential as a social system.

It is understood that soft complexity modelling resists quantification, yet Mesjasz (2010) makes a case for modelling soft complexity by making unquantifiable 
components measurable. This quantification process is indeed what quantitative researchers try to do when latent variables ${ }^{2}$ (predominantly in the affective learning domain) are defined by proxy, measurable variables. While in outdoor studies the contribution of qualitative research is seen as essential for an understanding of the complex process of learning (Allison and Pomeroy 2000), we might ask whether quantitative research can also make a contribution to the why and how of the process. This might be best approached through the use of correlation coefficients - notwithstanding the need to establish cause and effect - as exemplified in Nundy's (1999) work. Nundy found a statistical correlation between academic-affective (but not socialaffective) gain and cognitive gain amongst pupils, but only in the experimental group. This is what led him to believe that, "positive changes in affective learning appear to lead to positive changes in cognitive learning and that this is enhanced within a residential fieldwork setting" (p.193). Studies that yield correlation coefficients, path coefficients (in structural equation models), or regression weights, all have the potential to quantify the strength of relationships between components of the learning process.

\section{Quantification of affective and cognitive learning components}

Nundy's work remains a good example of primary research studies in which gain in social-affective, academic-affective and cognitive domains as a result of a combined adventure/curriculum course have been analysed for both effect sizes and correlations. Compared with the control group he found statistically-significant Cohen effect sizes ${ }^{3}$ for the experimental group of +0.08 for social-affective gain, +0.43 for academic affective gain and +1.58 for cognitive gain. This result is included in Table 1 along with a number of other statistically-significant effect sizes measured through primary studies or meta-analyses for learning in the affective and cognitive domains for adventure, curriculum and combined types of residential courses. The results in the Table give only a generalised picture, however, because they encompass a range of outcome measures, ages and genders of the participants, socio-economic or academic status of participants, venues, course durations and other variables, amongst other caveats. Nevertheless, whilst almost certainly not exhaustive, the Table reflects the fact that the bulk of quantitative evidence is in social affective gain from adventure courses, with relatively little published evidence of social affective gain from curriculum or combined courses.

Within the meta-analyses in Table 1, mean effect sizes include primary measures that range from -1.5 to +4.5 , although across the three different domains of learning the meta-analytic means are all within the range +0.23 to +0.62 , typical of means from educational interventions in general (Lipsey and Wilson 1993). The ability of outdoor education to deliver large effects in cognitive learning can be seen in the effects from primary studies, even when, in Fuller et al.'s (2017) case, the intervention was one of

\footnotetext{
${ }^{2}$ Latent variable. "A variable that cannot be directly measured but is assumed to be related to several variables that can be measured" (Field 2013, p.878). The measured variables are used to derive a score for the latent variable. Examples in outdoor education might be self-esteem or learner engagement.

${ }^{3}$ Effect size. "An objective and (usually) standardized measure of the magnitude of an observed effect. Measures include Cohen's $d$..." (Field 2013, p.874). Expressed mathematically, Cohen's $d$ is the difference between two means (such as (post-test mean - pre-test mean)) divided by the pooled standard deviation for the two data sets.
} 
Table 1 Mean Cohen effect sizes from meta-analyses (a) and primary studies (b) according to course type and learning domain. $\mathrm{c}=$ measured behaviour change rather than attainment

\begin{tabular}{|c|c|c|c|c|}
\hline $\begin{array}{l}\text { Cours e } \\
\text { type }\end{array}$ & Authors & $\begin{array}{l}\text { Social- affective } \\
\text { outcome measures }\end{array}$ & $\begin{array}{l}\text { Academic-affective } \\
\text { outcome measures }\end{array}$ & $\begin{array}{l}\text { Cogn itive } \\
\text { outcome } \\
\text { measures }\end{array}$ \\
\hline \multirow[t]{8}{*}{ Adventure } & Cason and Gillis (1994) ${ }^{a}$ & $+0.30,+0.34$ & +0.46 & +0.61 \\
\hline & Hattie et al. (1997) a & $+0.37,+0.32$ & $+0.38,+0.28$ & +0.46 \\
\hline & & All effects increased & in follow-up tests. & \\
\hline & Laidlaw (2000) a & +0.49 & & \\
\hline & Bunting and Donley (2002) a & $+0.23,+0.16$ & +0.58 & \\
\hline & Martin and Leberman,(2005) a & +0.74 & +0.61 & \\
\hline & Gillis and Speelman (2008) a & $\begin{array}{l}+0.26,+0.48 \\
\quad+0.29\end{array}$ & +0.37 & +0.26 \\
\hline & Fuller et al. $(2017)^{\mathrm{b}}$ & & & +1.28 \\
\hline \multirow[t]{2}{*}{ Curriculum } & Bogner $(1998,2002)^{\mathfrak{c}}$ & & $\begin{array}{l}\text { c. }+0.3 \text { in some } \\
\text { constructs }\end{array}$ & \\
\hline & Zelezny (1999) ac & & +0.62 & \\
\hline \multirow[t]{3}{*}{ Combined } & $\begin{array}{l}\text { Marsh and Richards }(1988)^{\mathrm{b}} \\
\text { (reported in Hattie et al. } \\
\text { (1997)) }\end{array}$ & & & +0.39 \\
\hline & Nundy $(1999)^{\mathrm{b}}$ & +0.08 & +0.43 & +1.58 \\
\hline & Sproule et al. $(2013)^{\mathrm{b}}$ & & $\begin{array}{l}+0.48 \text { (self- } \\
\quad \text { determination) }\end{array}$ & \\
\hline
\end{tabular}

adventure activities. Where means for cognitive learning are reported in meta-analyses they also tend to be slightly higher than means in other domains. Hattie et al. (1997, p.68), referring to a combined course, commented that "the effects on academic performance ... are most impressive ... where the aim [of the course] is to improve academic skills". There is clearly potential for adventure and combined courses to deliver cognitive gains during the course or back in school, but it is not yet clear from quantitative data that a curriculum course can deliver the putative affective learning that facilitates cognitive gain.

Several authors have investigated the quantitative relationship between components of residential courses, affective gain and cognitive gain through structural equation modelling. For example, using adventure courses and considering the affective domain, Propst and Koesler (1998) found that on-course mentoring, feedback and goal attainment impacted positively on a self-efficacy outcome; and Sibthorp and Arthur-Banning (2004) found that expectation and personal empowerment impacted positively on a life effectiveness outcome. Of particular interest here is research by Bailey and Kang (2015) with new university entrants, showing that participation in a wilderness orientation programme had a direct positive impact on informal social engagement, but this in turn did not have a direct influence over cognitive gain as measured by grade point average (GPA). On the other hand, participants' level of undirected reflection on a regular basis during the wilderness programme did have a positive influence over GPA. Given that the former is a social as opposed to personal phenomenon, it is possible that 
the social effect was dissipated during the first year at college. Nevertheless, Bailey and King go on to say that "the results illustrate the complexity of the WOP [wilderness orientation program] influence, indicating that the power of WOPs [on academic performance] may be mediated by social engagement and routine reflection" (p.219).

\section{Summary of existing research evidence}

At the level of the individual course participant the learning process is clearly a complex one involving feedforward, feedback and intertwining of learning in the affective and cognitive domains in response to multiple inputs. However, at the sample or population level, and in the eyes of the practitioner and customer, the process is often perceived as a linear one. Social and academic learning are perceived as facilitators of cognitive learning and cognitive gain. Adventure and combined residential courses have the ability to deliver the affective learning component, but it is less clear that a curriculum-related course can deliver this. With regard to quantitative research, more primary studies of correlational and related statistical measures of impact in all three domains of learning, ideally with evidence of cause and effect, are needed. The next section describes a small project using a curriculum course to discover if it could generate the social and academic affective learning that seems to facilitate cognitive gain.

\section{Quantitative testing the learning process}

\section{Rationale and methodology}

A small-scale quantitative study was undertaken to test for relationships between the elements of social-affective, academic-affective and cognitive learning associated with a residential curriculum (field studies) course. The research was conducted with 60 Year 4 Geography and Biology pupils from a Scottish secondary school. The intervention was a weekend (three days, two nights) residential course at the Millport Outdoor Centre on the Isle of Cumbrae to pursue fieldwork in coastal geomorphology and ecology. The project plan was to randomly assign the 60 pupils to demographically matched experimental and control groups (using gender and the Scottish Index of Multiple Deprivation (SIMD)). In actuality, the initial assignment of pupils to the experimental group was influenced by other pupil commitments over the weekend and was not random. In the process of creating two matched groups their size dropped to 25 , leading to some limitation on what could be achieved from the project.

To measure social-affective and academic-affective gain through pupil selfperception the ten ROPE (Review of Personal Effectiveness) factors of the ROPELOC questionnaire (Richards et al. 2002) were chosen and supplemented by two factors on learner engagement based on questions used in the Learning Away project (Kendall and Rodger 2015). Statements were scored on a Likert scale of 1 (this statement is completely untrue of me) to 6 (this statement is completely true of me). To measure cognitive gain, a test paper was designed by school staff in collaboration with Millport Centre staff comprising closed and open questions in coastal geomorphology and ecology and marked out of 20 by Millport staff. The school also provided general 
academic progress data to compare with the cognitive test scores. All responses were anonymised and matched using an alphanumeric code.

Testing was planned to provide pre-test and post-test measures of pupils' selfperception and subject knowledge just before and just after the November intervention. The pre-tests (called ROPE1 and COG1) took place as planned two weeks before the intervention. However, the post-tests (ROPE2 and COG2) had to be delayed because pupils were then engaged in preliminary examinations (for State Examinations later in the school year) and did not take place until February, nearly three months after the Millport field course. On the other hand, to introduce a longitudinal element into the project the ROPE questionnaire was administered again in late April (ROPE3). All tests were taken by all Year 4 Geography and Biology pupils, not just those in the experimental and control groups.

\section{Analysis and results}

Although the primary aim was to discover if the intervention delivered both affective and cognitive learning, and was therefore analysed for differences between the experimental and control groups, the opportunity was taken to analyse with gender in mind as a predictor of test scores. It was confirmed that the data distributions from all tests showed no significant departures from a normality and could therefore be analysed using parametric statistical methods.

\section{Review of personal effectiveness (affective learning)}

The ROPE data were analysed for reliability, across both individual factors and four factor groupings identified by Richards et al. (2002), here called dimensions (Tables 2 and 3). For most of the three-item factors Cronbach alpha ${ }^{4}$ values were comparable with published values. However, Active Involvement yielded a surprisingly low alpha value in all three tests. The individual questions within this factor refer to being either "energetic" or "involved", and it is possible that pupils did not interpret these two words as addressing the same concept (subsequent factor analyses of the ROPE data sets revealed cross loading from Active Involvement onto Social Abilities factors, particularly Cooperative Teamwork). Learner Engagement was a factor sourced from the Learning Away project, in which factor reliability had not been tested, and its lack of reliability here reflects this. The alpha values for the dimensions are mixed. Those for Organisational Skills are marginal despite the alphas for the constituent factors being good. This dimension, together with Active Involvement and factors Learner Engagement and Skills Development, relate to the academic-affective domain and noticeably have marginal alphas compared to constructs in the social-affective domain, possibly reflecting pupil uncertainty over their academic abilities.

Tables 4 and 5 show the mean scores on factors and dimensions for each test, presented in rank order. The mean scores and rank orders are remarkably similar from

\footnotetext{
${ }^{4}$ Cronbach's alpha. A measure of the reliability of a scale (the ROPE questionnaire in this case) to produce consistent results under different applications of the questionnaire. This measure can be calculated for the whole scale (Personal Effectiveness in this case) or for parts of the scale (such as the factor Cooperative Teamwork or the dimension Social Abilities). Values lie between 0 and 1, with $<0.6$ considered poor.
} 
Table 2 Cronbach alpha values for factors in the questionnaire used to test pupils' self-perception in areas of affective learning ${ }^{\mathrm{a}}$

\begin{tabular}{lllll}
\hline Factor & ROPE1 $(N=58)$ & ROPE2 $(\mathrm{N}=60)$ & ROPE3 $(\mathrm{N}=58)$ & Published \\
\hline AI (Active Involvement) & .46 & .57 & .49 & $.80 / .76$ \\
CT (Cooperative Teamwork) & .92 & .90 & .93 & $.85 / .88$ \\
LA (Leadership Ability) & .92 & .90 & .92 & $.91 / .91$ \\
OT (Open Thinking) & .60 & .65 & .70 & $.83 / .81$ \\
QS (Quality Seeking) & .67 & .84 & .80 & $.85 / .84$ \\
SC (Self Confidence) & .85 & .83 & .87 & $.84 / .82$ \\
SelfE (Self Efficacy) & .89 & .91 & .95 & $.87 / .87$ \\
SocE (Social Efficacy) & .89 & .92 & .84 & $.88 / .87$ \\
TM (Time Management) & .78 & .89 & .88 & $.86 / .88$ \\
CC (Coping with Change) & .92 & .95 & .95 & $.93 / .87$ \\
LE (Learner Engagement) & .47 & .53 & .61 & Not available \\
SD (Skills Development) & .66 & .73 & .61 & Not available \\
\hline
\end{tabular}

${ }^{a}$ Published values are taken from Richards et al. (2002)

test to test. In all three deliveries of the questionnaire the highest mean factor scores are in the same five factors (Quality Seeking, Learner Engagement, Open Thinking, Active Involvement, Cooperative Teamwork), which seem to relate more closely with academic self-perception, and the lowest mean scores are in the same four factors (Social Efficacy, Time Management, Coping with Change, Self-Efficacy), notably including both personal and social elements. This separation between groups of high-scoring and low-scoring factors is statistically-significant in all three tests $(d \approx 0.5, p<0.01)$; amongst dimensions, Active Involvement is statistically stronger than others $(d \approx 0.7$, $p<0.05$ ). These results present a clear and consistent view from pupils of where they feel effective in life and where they feel less effective through the school year. When factors are grouped into dimensions, mean scores show a similar consistency of rank order from test to test, both for all pupils and for the experimental and control groups.

Statistical analysis for differences between tests and groups was carried out with matched pupils. There is a statistically-significant fall $(d \approx-0.2, p<0.02)$ in mean scores from ROPE1 to ROPE2 $(N=50)$, which is particularly clear in Table 4 . The fall in scores in ROPE2 occurs for both the experimental and control groups (Table 5), and for both boys and girls. This is an important result, because the Millport experiment

Table 3 Cronbach alpha values for dimensions (factor groupings)

\begin{tabular}{llll}
\hline Dimension (constituent factors) & ROPE1 (N=58) & ROPE2 (N=60) & ROPE3 (N=58) \\
\hline Active Involvement (AI) & .46 & .57 & .49 \\
Social Abilities (SocE, CT, LA) & .84 & .86 & .80 \\
Organisational Skills (TM, QS, CC) & .51 & .63 & .51 \\
Personal Abilities and Beliefs & .78 & .75 & .70 \\
(SC, SelfE, OT) & & & \\
\hline
\end{tabular}


Table 4 Mean scores and standard deviations for all pupils in factors, presented in rank order

\begin{tabular}{|c|c|c|c|c|c|}
\hline \multicolumn{2}{|c|}{ ROPE1 $(N=58)$} & \multicolumn{2}{|c|}{ ROPE2 $(N=60)$} & \multicolumn{2}{|c|}{ ROPE3 $(\mathrm{N}=58)$} \\
\hline QS & $5.15 \pm 0.66$ & QS & $5.00 \pm 0.90$ & QS & $5.07 \pm 0.62$ \\
\hline LE & $5.06 \pm 0.61$ & LE & $4.89 \pm 0.80$ & LE & $4.93 \pm 0.69$ \\
\hline OT & $4.89 \pm 0.66$ & $\mathrm{AI}$ & $4.76 \pm 0.75$ & OT & $4.84 \pm 0.56$ \\
\hline AI & $4.76 \pm 0.90$ & OT & $4.75 \pm 0.65$ & AI & $4.79 \pm 0.65$ \\
\hline $\mathrm{CT}$ & $4.72 \pm 1.12$ & $\mathrm{CT}$ & $4.63 \pm 1.05$ & $\mathrm{CT}$ & $4.77 \pm 0.95$ \\
\hline LA & $4.67 \pm 1.15$ & SD & $4.59 \pm 0.90$ & LA & $4.66 \pm 0.93$ \\
\hline SC & $4.64 \pm 0.91$ & $\mathrm{SC}$ & $4.56 \pm 0.99$ & SD & $4.66 \pm 0.70$ \\
\hline SD & $4.64 \pm 0.89$ & LA & $4.55 \pm 1.04$ & $\mathrm{SC}$ & $4.61 \pm 0.85$ \\
\hline SocE & $4.32 \pm 0.99$ & SocE & $4.36 \pm 1.02$ & SocE & $4.34 \pm 0.81$ \\
\hline $\mathrm{TM}$ & $4.29 \pm 0.85$ & $\mathrm{TM}$ & $4.23 \pm 0.94$ & $\mathrm{CC}$ & $4.28 \pm 1.11$ \\
\hline $\mathrm{CC}$ & $4.12 \pm 1.12$ & $\mathrm{CC}$ & $4.03 \pm 1.13$ & $\mathrm{TM}$ & $4.22 \pm 0.89$ \\
\hline SelfE & $3.92 \pm 1.02$ & SelfE & $3.97 \pm 1.04$ & SelfE & $4.04 \pm 1.04$ \\
\hline
\end{tabular}

See Table 2 for factor names

was conducted to discover whether a residential curriculum-related course could engender learning in the affective domain. To measure a significant fall following a residential intervention is unusual (only $14.5 \%$ of the effect sizes used in their metaanalysis by Hattie et al. (1997) were negative). In this case, it is possible that the preliminary state exams conducted between the tests created amongst pupils a more conservative view of their personal effectiveness. Mean scores recovered a little from ROPE2 to ROPE3 $(N=48)$.

Table 5 Mean scores and standard deviations for dimensions (factor groupings)

\begin{tabular}{|c|c|c|c|c|c|c|}
\hline \multicolumn{3}{|l|}{ Dimensions } & $\begin{array}{l}\text { ROPE1 } \\
\qquad(N=58)\end{array}$ & $\begin{array}{l}\text { ROPE2 } \\
\qquad(N=60)\end{array}$ & \multicolumn{2}{|c|}{ ROPE3 (N = 58) } \\
\hline \multicolumn{3}{|l|}{ Active Involvement (AI) } & $4.76 \pm 0.90$ & $4.75 \pm 0.65$ & \multicolumn{2}{|l|}{$4.79 \pm 0.65$} \\
\hline \multicolumn{3}{|l|}{ Social Abilities (SocE, CT, LA) } & $4.57 \pm 0.94$ & $4.52 \pm 0.92$ & \multicolumn{2}{|l|}{$4.59 \pm 0.76$} \\
\hline \multicolumn{3}{|c|}{ Organisational Skills (TM, QS, CC) } & $4.52 \pm 0.64$ & $4.42 \pm 0.76$ & \multicolumn{2}{|l|}{$4.53 \pm 0.64$} \\
\hline \multicolumn{3}{|c|}{ Personal Abilities and Beliefs (SC, SelfE, OT) } & $4.48 \pm 0.73$ & $4.42 \pm 0.74$ & \multicolumn{2}{|l|}{$4.50 \pm 0.67$} \\
\hline \multirow[t]{2}{*}{ Dimensions } & \multicolumn{3}{|c|}{ Experimental Group $(N=25)$} & \multicolumn{3}{|c|}{ Control Group $(\mathrm{N}=25)$} \\
\hline & ROPE1 & ROPE2 & ROPE3 & ROPE1 & ROPE2 & ROPE3 \\
\hline Active Involvement (AI) & $5.06 \pm 0.76$ & $4.98 \pm 0.71$ & $4.89 \pm 0.62$ & $4.62 \pm 0.79$ & $4.52 \pm 0.66$ & $4.68 \pm 0.68$ \\
\hline $\begin{array}{l}\text { Social Abilities (SocE, CT, } \\
\text { LA) }\end{array}$ & $4.74 \pm 0.93$ & $4.45 \pm 0.98$ & $4.57 \pm 0.85$ & $4.43 \pm 0.84$ & $4.44 \pm 0.93$ & $4.53 \pm 0.79$ \\
\hline $\begin{array}{l}\text { Organisational Skills (TM, } \\
\text { QS, CC) }\end{array}$ & $4.49 \pm 0.65$ & $4.43 \pm 0.65$ & $4.50 \pm 0.70$ & $4.52 \pm 0.63$ & $4.44 \pm 0.79$ & $4.58 \pm 0.63$ \\
\hline $\begin{array}{l}\text { Personal Abilities and Beliefs } \\
\quad(\mathrm{SC}, \text { SelfE, OT })\end{array}$ & $4.57 \pm 0.66$ & $4.41 \pm 0.74$ & $4.45 \pm 0.80$ & $4.51 \pm 0.70$ & $4.35 \pm 0.79$ & $4.51 \pm 0.59$ \\
\hline
\end{tabular}

Upper part: all pupils; lower part: experimental and control groups only 


\section{Results of cognitive learning tests}

The two cognitive tests (COG1 and COG2) were marked out of 20 by the outdoor learning teacher at Millport Field Centre. Table 6 shows mean scores and standard deviations for the two tests and the effect sizes for the improvement in scores for different cohorts of pupils. Marks increased substantially from pre-test to post-test in a statistically-significant way $(p<0.01)$ for all cohorts, but they were almost certainly inflated to some extent by the fact that the tests were either side of the revision period for the preliminary state examinations. Nevertheless, the exceptional improvement in score for the experimental group relative to the control group $(d=0.6, p=0.05)$ is consistent with research showing that residential courses wholly or partly dedicated to curriculum work deliver strong cognitive gain.

\section{Combining evidence from measures of affective and cognitive learning}

A key objective of this experiment was to investigate whether a residential curriculum-related course was able to deliver the social-affective and academicaffective learning that seems to facilitate cognitive gain. Outdoor education practitioners and customers tend to see this as a linear process of learning, but at the level of the individual participant the process is a complex one of intertwining learning domains. The course did deliver a significant improvement in cognitive gain for the experimental group over the control group, but no evidence of affective learning for either group - in fact there was a significant fall in pupils' view of their personal effectiveness in affective domains. To understand this situation more fully, and to find out if ROPE scores predicted COG scores in any way, a series of correlational and linear multivariate regression tests was carried out. The regressions are based on the assumption that affective learning facilitates cognitive learning. In these, ROPE21 = (ROPE post-test mean score $)-$ (ROPE pre-test mean score), and COG $21=(\mathrm{COG}$ post-test mean score $)-(\mathrm{COG}$ pre-test mean score); "group" means experimental or control group.

- Using all matched pupils, there was no statistically-significant correlation of pupils' scores between ROPE21 and COG21. Controlling for gender and/or group yielded the same non-significant result. For these test, typically $r \approx 0.2, p \approx 0.2(N=50)$.

- Analysing the experimental and control groups separately produced the same results, but with $p \approx 0.35(N=24)$.

Table 6 Mean scores and standard deviations for the cognitive tests, marked out of 20

\begin{tabular}{llll}
\hline Cohort of pupils & Pre-test $(\mathrm{COG} 1)$ & Post-test $(\mathrm{COG} 2)$ & Cohen's Effect Size \\
\hline All matched pupils & $11.7 \pm 3.2(N=52)$ & $14.2 \pm 3.0(\mathrm{~N}=52)$ & 0.8 \\
Experimental group & $11.2 \pm 2.6(N=24)$ & $14.5 \pm 2.7(\mathrm{~N}=24)$ & 1.2 \\
Control group & $12.8 \pm 3.3(\mathrm{~N}=24)$ & $14.4 \pm 3.0(\mathrm{~N}=24)$ & 0.5 \\
All boys & $11.8 \pm 3.9(N=20)$ & $14.4 \pm 3.6(\mathrm{~N}=20)$ & 0.7 \\
All girls & $11.6 \pm 2.8(\mathrm{~N}=37)$ & $14.0 \pm 2.7(N=37)$ & 0.9 \\
\hline
\end{tabular}


- Using all matched pupils, the regression COG21 = $f$ (ROPE21, group, gender) to test for the dependence of COG21 scores on ROPE21 scores was non-significant.

- Analysing experimental and control groups separately, the regression COG21 = $f$ (ROPE21, gender) was non-significant.

- However, for genders separately, COG21 = $f$ (ROPE21, experimental/control group) was significant for the effect of ROPE21 on COG21 for boys but not girls (Table 7)

These regression analyses were also conducted for each of the four dimensions of Active Involvement, Social Abilities, Organisational Skills and Personal Abilities and Beliefs with much the same results. Throughout, despite COG21 scores being very group-dependent (see Table 6), the Group variable is only ever statistically-significant at $p=0.08$.

For all pupils ROPE21 mean scores tend to be negative and COG21 mean scores tend to be positive, therefore, for boys, as the change in ROPE2 1 becomes less negative the change in COG21 becomes more positive, i.e. there is a positive relationship between affective gain and cognitive gain. The fact that this does not apply to girls is interesting, given that elsewhere in the data there are no significant differences in the performance of boys and girls. Although there is an increasing research interest in gender and outdoor education, this primarily focuses on adventure activities and affective outcomes without taking the step of relating these to cognitive gain.

Table 7 Coefficients for the linear regression model, COG21 $=f$ (ROPE21, experimental/control group) for boys and for girls

\begin{tabular}{llll}
\hline $\begin{array}{l}\text { Boys } \\
\text { Model (Step) } 1\end{array}$ & B (coefficient) & Standard error of B & $\beta$ (standardised coefficient) \\
Constant & 2.32 & 0.48 & \\
ROPE21 & 0.93 & 0.29 & $0.81^{*}$ \\
Model (Step) 2 & & 1.52 & \\
Constant & 3.87 & 0.29 & $0.58^{*}$ \\
ROPE21 & 0.88 & 0.93 & -0.21 \\
Group & -1.01 & Standard error of B & $\beta$ (standardised coefficient) \\
Girls & & & \\
Model (Step) 1 & B (coefficient) & 0.60 & -0.11 \\
Constant & 2.43 & 0.40 & \\
ROPE21 & -0.24 & & 0.00 \\
Model (Step) 2 & & 1.90 & -0.24 \\
Constant & 4.80 & 0.39 & \\
ROPE21 & 0.00 & 1.18 & \\
Group & -1.55 & & \\
\hline
\end{tabular}

${ }^{\text {a }} \mathrm{R}^{2}$ (Model 1) $=0.38 ; \Delta \mathrm{R}^{2}=0.04$ for Model $2(p=0.01) ; * p<0.01 ; d f=18$

b $\mathrm{R}^{2}$ (Model 1) $=0.00 ; \Delta \mathrm{R}^{2}=0.06$ for Model $2(p=0.43) ; d f=31$ 


\section{Discussion: The role of self-concept in the learning process}

The attempt here to find out if a purely curriculum course has the ability to engender an affective learning component, and thus reinforce the idea of an interaction between affective and cognitive learning domains during the learning process, was not very successful. Pre- and post-tests either side of the Millport intervention did measure significantly greater cognitive gain for the experimental group over the control group but no statistically-significant gain in social-affective or academic-affective learning for either of the groups. In fact, pupils recorded a fall in their self-perception in the affective domain following the intervention, perhaps because of some anxiety around important examinations at the time. However, for boys in the experimental group the extent of this fall correlated positively with their cognitive gain, i.e. the smaller the fall the better the cognitive performance.

Interestingly, the results from the three deliveries of the Review of Personal Effectiveness (ROPE) questionnaire indicated a high degree of stability in the rank order of pupils' mean scores in factors and dimensions over the six-month testing period. This similarity of rank orders prompted an investigation into the stability of pupil selfperception over the testing period. Because ROPE was developed as an instrument to measure self-concept as reflected in behaviours, this investigation focused on stability of self-concept. Pupil self-concept is seen as an "important [multi-dimensional] construct within ... education because of the interaction of affective and cognitive dimensions on students' behaviour and learning" (Hay and Ashman 2003: 78). Much of the research in this area is concerned with stability of self-concept on different time-scales (e.g. Cole et al. 2001; Trzesniewski et al. 2003; Kuster and Orth 2013). Self-concept seems to become more stable through teenage years and is then stable on a scale of years but declines into old age. Over the timescale of six months observed here, shortterm instability is a common observation and thought to be the result of psychological response to short-term 'environmental events'.

Table 8 gives unattenuated test-retest rank order correlation coefficients for stability and the Cronbach alpha values for the dimensions derived from Richards et al. (2002) (alpha can be used to correct for reliability-related attenuation of the coefficients). Given that typical unattenuated coefficients for adolescents over these short periods are in the range 0.4 to 0.7 , here we see reasonably strong stability in all dimensions over both three- and six-month periods, with the exception of a value of 0.47 for Organisational Skills over six months. Stability in the areas of Personal and Social Abilities appears to be particularly strong. On the other hand, stability in the Organisational Skills dimension, interpreted here as an academic-affective construct and therefore potentially responsive to academic events, might have been influenced by anxiety around important examinations. When analysis is conducted at the group level, Social Abilities remains a stable dimension for both experimental and control groups; Active Involvement and Organisational Skills are somewhat more stable for the experimental group and Personal Abilities for the control group. There is no clear evidence from these data that the Millport intervention acted as an environmental event affecting the short-term stability of the experimental group.

On the basis of such a small-scale and less-than-perfect experiment these inferences are somewhat speculative, but it is interesting to compare learning measured by testretest effect sizes with stability measured by test-retest correlations. These two 
Table 8 Unattenuated test-retest rank order correlations for short-term stability of self-concept for dimensions, and Cronbach alpha reliabilities for each test

\begin{tabular}{|c|c|c|c|c|c|}
\hline Dimension & Test & ROPE1 & ROPE2 & ROPE3 & Cronbach's $\alpha$ \\
\hline \multirow{3}{*}{$\begin{array}{l}\text { Active Involvement } \\
\text { (3 items) }\end{array}$} & ROPE1 & & & & 0.46 \\
\hline & ROPE2 & 0.65 & 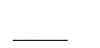 & & 0.57 \\
\hline & ROPE3 & 0.65 & 0.61 & 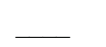 & 0.49 \\
\hline \multirow{3}{*}{$\begin{array}{l}\text { Social Abilities } \\
\text { (9 items) }\end{array}$} & ROPE1 & 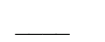 & & & 0.84 \\
\hline & ROPE2 & 0.78 & 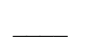 & & 0.86 \\
\hline & ROPE3 & 0.79 & 0.78 & 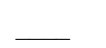 & 0.80 \\
\hline \multirow{3}{*}{$\begin{array}{l}\text { Organisational Skills } \\
\text { (9 items) }\end{array}$} & ROPE1 & - & & & 0.51 \\
\hline & ROPE2 & 0.63 & 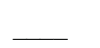 & & 0.63 \\
\hline & ROPE3 & 0.47 & 0.77 & $\underline{-}$ & 0.51 \\
\hline \multirow{3}{*}{$\begin{array}{l}\text { Personal Abilities and Beliefs } \\
\text { (9 items) }\end{array}$} & ROPE1 & 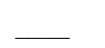 & & & 0.78 \\
\hline & ROPE2 & 0.72 & 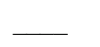 & & 0.75 \\
\hline & ROPE3 & 0.70 & 0.86 & 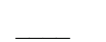 & 0.70 \\
\hline
\end{tabular}

measures do not necessarily go hand in hand. With regard to learning in the affective domain, no learning was measured in the experimental group following from the Millport intervention. On the other hand, there was strong stability in rank order of the mean scores in the factors and dimensions of the questionnaire (Table 4) and relatively strong stability of self-concept in the rank order of pupils from test to test (Table 8). An interesting question is whether the strength of short-term stability of selfconcept observed here inhibited gain for the experimental group in the affective domain. Data with which to test this idea is rare in the research literature, but Table 1 of Kuster and Orth (2013) does provide an opportunity and shows that stability of selfesteem (rather than self-concept) between tests (long-term in this case) does indeed correlate inversely with change in mean scores (Spearman's rho, $\rho=-0.5, p=0.06$ ). Without further evidence, this is too big a question to pursue now, but it is a fascinating area for research. Or is it simply the case that a curriculum course, whilst delivering strong improvements in cognitive learning, is not capable of eliciting the affective learning that is thought to facilitate it? The point remains that there are very few primary quantitative studies in the research literature that are specifically designed to test the suggestion that learning in the affective domain is a desirable facilitator for learning in the cognitive domain. Such studies have the potential to inform the how and why of learning, by using correlational and related statistical analysis, in addition to establishing what works and by how much.

\section{Conclusions, and a call for targeted quantitative studies}

In the research literature and various project reports there are rather different views of pupils' process of learning on residential outdoor education courses. Those who are engaged with delivering residential outdoor education and those who make use of measures of effectiveness to justify policy and practice, often simplify the process to a 
linear, or quasi-linear, one. This might be adequate for practical purposes, with normative measures of gain in the social-affective, academic-affective and cognitive components of the process provided by quantitative research. On the other hand, for researchers who are engaged in understanding the process at a deeper level with the aim of improving delivery, policy and practice, as well as a better understanding of experiential learning in general, the process is a complex one, involving intertwining of domains, feedback as well as feedforward, and cycles. Soft complexity, recognised at individual or organisational levels, might be an appropriate term to use because it incorporates the different ways of seeing the world that come from the individual participant, such as prior experiences, motivations, learning preferences and behaviours.

Quantitative studies in outdoor education can make a valuable contribution to this discussion by demonstrating that learning does indeed take place concomitantly in affective and cognitive domains across the different types of residential courses. There is some evidence of this, but much more is needed. Primary studies that take a quasiexperimental approach using appropriate instruments to measure social-affective, academic-affective and cognitive learning have the ability to do this. For studies with a longitudinal element, it is possible to interpret affective learning in the context of stability of general self-concept.

Open Access This article is distributed under the terms of the Creative Commons Attribution 4.0 International License (http://creativecommons.org/licenses/by/4.0/), which permits unrestricted use, distribution, and reproduction in any medium, provided you give appropriate credit to the original author(s) and the source, provide a link to the Creative Commons license, and indicate if changes were made.

\section{References}

Allison, P., \& Pomeroy, E. (2000). How shall we "know?" epistemological concerns in research in experiential education. The Journal of Experimental Education, 23(2), 91-98.

Amos, R., \& Reiss, M. (2012). The benefits of residential fieldwork for school science: Insights from a fiveyear initiative for inner-city students in the UK. International Journal of Science Education, 34(4), 485511.

Bailey, A. W., \& Kang, H.-K. (2015). Modeling the impact of wilderness orientation programs on first-year academic success and life purpose. Journal of Adventure Education and Outdoor Learning, 15(3), 209233.

Bloom, B. S., Engelhart, M. D., Furst, E. J., Hill, W. H., \& Krathwohl, D. R. (1956). Taxonomy of educational objectives: The classification of educational goals. Handbook I: Cognitive domain. New York: David McKay Company.

Bogner, F. X. (1998). The influence of short-term outdoor ecology education on long-term variables of environmental perspective. The Journal of Environmental Education, 29(4), 17-29.

Bogner, F. X. (2002). The influence of a residential outdoor education programme on pupils' environmental perception. European Journal of Psychology of Education, 17(1), 19-34.

Boyle, A., Maguire, S., Martin, A., Milson, C., Nash, R., Rawlinson, S., et al. (2007). Fieldwork is good: The student perception and the affective domain. Journal of Geography in Higher Education, 31(2), 299-317.

Bunting, C. J., \& Donley, J. P. (2002). Ten years of challenge course research: A review of affective outcome studies. In Abstract, $6^{\text {th }}$ Coalition for the Education in the Outdoors research symposium. Bradford: Woods.

Cason, D., \& Gillis, H. L. (1994). A meta-analysis of outdoor adventure programming for adolescents. The Journal of Experimental Education, 17(1), 40-47. 
Christie, E. M., \& Higgins, P. (2012). The impact of outdoor learning experiences on attainment and behaviour: A brief review of literature. (forestry commission report 11/2012). Edinburgh: Forestry Commission Scotland/University of Edinburgh.

Cilliers, P., \& Richardson, K. A. (2001). What is complexity science? A view from different directions. Emergence, 3(1), 5-23.

Cole, D. A., Maxwell, S. E., Martin, J. M., Peeke, L. G., Seroczynski, A. D., Tram, J. M., et al. (2001). The development of multiple domains of child and adolescent self-concept: A cohort sequential longitudinal design. Child Development, 72(6), 1723-1746.

Davis, B., \& Sumara, D. (2006). Complexity and education: Inquiries into learning, teaching and research. Mahwah: Erlbaum.

Durlak, J. A., Weissberg, R. P., \& Pachan, M. (2010). A meta-analysis of after-school programs that seek to promote personal and social skills in children and adolescents. American Journal of Community Psychology, 45, 294-309.

Durlak, J. A., Weissberg, R. P., Dymnicki, A., Taylor, R., \& Schellinger, K. (2011). The impact of enhancing students' social and emotional learning: A meta-analysis of school-based universal interventions. Child Development, 82(1), 405-432.

Dweck, C. S., \& Leggett, E. L. (1988). A social-cognitive approach to motivation and personality. Psychological Review, 95(2), 256-273.

Elkins, J. T., \& Elkins, N. M. L. (2007). Teaching geology in the Field: Significant geoscience concept gains in entirely Field-based introductory geology courses. Journal of Geoscience Education, 55(2), 126-132.

Experience Outdoors (n.d.). Retrieved from https://www.experienceoutdoors.org.uk/residential/field. Accessed 01 June 2019.

Field, A. (2013). Discovering statistics using IBM SPSS statistics (4th ed.915 pp). London: SAGE.

Fiennes, C., Oliver, E., Dickson, K., Escobar, D., Romans, A. \& Oliver, S. (2015). The existing evidence base about the effectiveness of outdoor learning (73pp. Rep.). London: Institute of Education, University College London.

Fuller, C., Powell, D., \& Fox, S. (2017). Making gains: The impact of outdoor residential experiences on students' examination grades and self-efficacy. Educational Review, 69(2), 232-247.

Gillis, H. L., \& Speelman, E. (2008). Are challenge (ropes) courses an effective tool? A meta-analysis. The Journal of Experimental Education, 31(2), 111-135.

Hattie, J., Marsh, H. W., Neill, J. T., \& Richards, G. E. (1997). Adventure education and outward bound: Outof-class experiences that have a lasting effect. Review of Educational Research, 67, 43-87.

Hay, I., \& Ashman, A. F. (2003). The development of adolescents' emotional and general self-concept: The interplay of parents, peers and gender. International Journal of Disability, Development and Education, 50(1), 77-91.

Kendall, S., \& Rodger, J. (2015). Evaluation of learning Away: Final report (106pp + annexes. Rep.). London: Paul Hamlyn Foundation.

Krathwohl, D. R., Bloom, B. S., \& Masia, B. B. (1964). Taxonomy of educational objectives handbook II: Affective domain (196 pp). London, Longmans: Green and Co.Ltd.

Kuster, F., \& Orth, U. (2013). The long-term stability of self-esteem: Its time-dependent decay and nonzero asymptote. Personality and Social Psychology Bulletin, 39(5), 677-690.

Laidlaw, J.S. (2000). A Meta-Analysis of Outdoor Education Programs. Unpublished PhD thesis, University of Northern Colorado,

Learning Away (n.d.). What makes a brilliant residential? Retrieved from http://learningaway.org.uk/the campaign/what-makes-a-brilliant-residential/. Accessed 01 June 2019.

Lipsey, M. W., \& Wilson, D. B. (1993). The efficacy of psychological, educational and behavioral treatment. American Psychologist, 49(12), 1181-1209.

Malone, K., \& Waite, S. (2016). Student outcomes and natural schooling. Plymouth: Plymouth University. Available online http://www.plymouth.ac.uk/research/oelres.net. .

Marsh, H. W., \& Richards, G. E. (1988). The outward bound bridging course for low-achieving high-school males: Effect of academic achievement and multidimensional self-concepts. Australian Journal of Psychology, 40, 281-298.

Martin, A.J. \& Leberman, S.I. (2005). Personal Learning or Prescribed Educational Outcomes: A Case Study of the Outwrad Bound Experience. Journal of Experiential Education, 28(1), 44-59.

McKenzie, M. (2003). Beyond "the outward bound process": Rethinking student learning. The Journal of Experimental Education, 26(1), 8-23.

Mesjasz, C. (2010). Complexity of social systems. Acta Physica Polonica A, 117(4), 706-715.

Nundy, S. (1999). The fieldwork effect: The role and impact of fieldwork in upper primary school. International Journal of Geographical and Environmental Education, 8, 190-198. 
Propst, D. B., \& Koesler, R. A. (1998). Bandura goes outdoors: Role of self-efficacy in the outdoor leadership development process. Leisure Sciences, 20(4), 319-344.

Richards, G.E., Ellis, L.A. \& Neill, J.T. (2002). The ROPELOC: Review of personal effectiveness and locus of control. http://www.wilderdom.com/tools/leq/ROPELOC.html. .

Schenck, J., \& Cruickshank, J. (2015). Evolving Kolb: Experiential education in the age of neuroscience. The Journal of Experimental Education, 38(1), 73-95.

Scrutton, R. A. (2014). Evidence for a "pathway" of learning for school children on residential outdoor education courses. Horizons, 67, 12-15.

Sibthorp, J., \& Arthur-Banning, S. (2004). Developing life-effectiveness through adventure education: The roles of participant expectations, perceptions of empowerment and learning relevance. The Journal of Experimental Education, 27(1), 32-50.

Sproule, J., Martindale, R., Wang, J., Allison, P., Nash, C., \& Gray, S. (2013). Investigating the experience of outdoor and adventurous project work in an educational setting using a self-determination framework. European Physical Education Review, 19(3), 315-328.

Trzesniewski, K. H., Dobbellan, M. B., \& Robins, R. W. (2003). Stability of self-esteem across the life span. Journal of Personality and Social Psychology, 84(1), 205-220.

Waite, S., Passey, R., Gilchrist, M., Hunt, A. \& Blackwell, I. (2016). Natural connections demonstration project, 2012-2016: Final report. Natural England commissioned reports, no.215.

Williams, R. (2013). Woven into the fabric of experience: Residential adventure education and complexity. Journal of Adventure Education and Outdoor Learning, 13(2), 107-124.

Zelezny, L. (1999). Educational interventions that improve environmental behaviors: A meta-analysis. Journal of Environmental Education, 31(1), 5-14.

Publisher's note Springer Nature remains neutral with regard to jurisdictional claims in published maps and institutional affiliations.

Roger Scrutton is Honorary Research Fellow in Outdoor Education at the University of Edinburgh, UK. He was previously on the academic staff in Geosciences at Edinburgh, where the personal, social and academic benefits of residential fieldwork for university students were clear. His current research investigates such benefits for school pupils using quantitative research methodologies. 